\title{
Girl (Not) Gone
}

\author{
Claudia Mitchell
}

\section{$\cos 80$}

This special issue of Girlhood Studies, close to double the length of previous issues, offers a blockbuster of articles on the theme of the girl in the text, guest edited by our managing editor, Ann Smith. As the third in the Girlhood Studies 10th anniversary collection, this issue brings together several ideas. This special issue was inspired in part by the spate of novels over the last few years that draw attention to the girl in their titles. Those featuring teenaged girls range from Girl with a Pearl Earring, a historical romance about a teenage girl to the dystopian thriller, Wind-Up Girl, and from The Girl with all the Gifts, a zombie horror story, to Don't Judge a Girl by her Cover, a young adult mystery novel centered on a girls' school for teenage spies. And then we have those featuring women like Girl Gone and The Girl on the Train. At another level, however, it was inspired by a much broader conceptualization of the notion of the girl in the text that includes the consideration of girls who are actually in texts in the sense of having produced literary, political, or visual texts themselves, the exploration of representations of girls in literary texts (for children and young people as well as those that target adults), and investigation into how girls are constructed in transactional texts written for girls about girlhood, like the Puberty Books that deal primarily with girls' experiences of bodily change and menstruation, and other guides and manuals. These all stand in proud opposition to the policy texts that silence girls in that they so often determine, without reference to girls themselves, who is included or excluded from programs in schools, access to health care, and so on.

A recent girl-in-the-text policy document published in 2015 by The United Nations Population Fund (UNFPA), Ten: How Our Future Depends on a Girl at This Decisive Age, looks at the success of the ten-year-old girl as the indicator or bench mark for the Sustainable Development Goals for 2030, locating the girl in the text in a quite different way. As Babatunde Osotimehin, Executive Director, UNFPA, comments in the preface to the 
report, "In many ways, a ten-year-old girl's life trajectory will be the true test of whether the 2030 Agenda is a success_-or failure" (2015: n.p.).

This is an opportune moment for me to announce that this anniversary celebration heralds the extension of Girlhood Studies: An Interdisciplinary Journal into a new publishing project with Berghahn Press-a book series called Transnational Girlhoods. As we have seen over the last decade, girlhood studies has emerged as a strong area of interdisciplinary research and activism, encompassing studies of feminism, women and gender, and childhood and youth, and extending into such areas as sociology, anthropology, history, development studies, literary studies, and media and cultural studies. As the first book series to focus specifically on this exciting field, Transnational Girlhoods will help to advance the research and activism agenda by publishing full-length monographs and edited collections that reflect a robust interdisciplinary and global perspective. International in scope, the series will draw on a vibrant network of girlhood scholars already active across North America, Europe, Russia, Oceania, and Africa, while forging connections with new activist and scholarly individuals and communities. Transnational Girlhoods ${ }^{1}$ is now officially accepting submissions, with the first books in the series to be published late in 2018 and early in 2019.

\section{Note}

1. https://www.berghahnbooks.com/series/transnational-girlhoods

\section{Reference}

Osotimehin, Babatunde. 2015. Ten: How Our Future Depends on a Girl at This Decisive Age. The United Nations Population Fund (UNFPA). http://www. unfpa.org/swop (accessed 30 September 2017). 